\title{
Tackling AMR crisis in India: Changing paradigm
}

\author{
Sandeep Lahiry', Rajesh Ramalingam², Krunal Dalal ${ }^{3}$, Ashwini Pawar ${ }^{4}$, Yashpal Chugh $^{5}$, \\ Alap Gandhi', Bhavesh Kotak ${ }^{7}$ \\ ${ }^{1}$ Medical Advisor, ${ }^{2}$ Senior Medical Advisor, ${ }^{3}$ Therapy Lead (Anti-infectives), ${ }^{4}$ Head Medical Affairs, ${ }^{5}$ Global Medical \\ Lead (Anti-infectives), ${ }^{7}$ Country Medical Director, GlaxoSmithKline (India), ${ }^{6}$ Country Medical Director, GlaxoSmithKline \\ (Malaysia)
}

\section{A B S T R A C T}

Antimicrobial resistance (AMR) is an important public health concern globally. For India, undoubtedly, AMR has had profound impact on its health \& socioeconomic parameters. Several hospital and community-based surveys have indicated alarming rise in incidence of multidrug resistant microbes, especially 'superbugs', having direct links with antibiotic use/misuse. Additionally, paucity in data with regards to quantification of AMR crisis \& its determinants has been concerning. However, the national commitment to address AMR has steadily increased of late, with an oft-restated realization - it is time to act. Recent initiatives like National Policy for Containment of AMR (2011), Chennai Declaration (2012), Anti-microbial Resistance Surveillance and Research Network (2013), The Red Line Campaign (2016), National Action Plan (NAP) for AMR (2017), ICMR Treatment Guidelines for Antimicrobial Use in Common Syndromes (2019) are promising measures expected to have positive impact on both clinical and economic outcome in India. This paper provides a snapshot of major strategies proposed in recent years, including educational and awareness initiatives, infection control guidelines, audit and feedback, antimicrobial stewardship, surveillance projects etc. It also identifies technical challenges \& opportunities for improved AMR mitigation in India.

Key words: Antibiotics; Antibiotic resistance; Knowledge; Rational use; Challenges; India

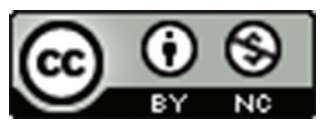

This work is licensed under a Creative Commons Attribution-NonCommercial 4.0 International License.

\section{INTRODUCTION}

Infectious disease burden in India is among the highest in the world, including those caused by multi-drug resistant (MDR) pathogens. The crude mortality rate from infectious disease in India today is nearly 417 per 100,000 persons. ${ }^{1}$ Antibiotic-resistant strains have emerged among both Gram-positive and Gram-negative pathogens. Meta-analysis of drug susceptibility data from several Indian laboratories show increasing antimicrobial resistance (AMR) against pathogens like Staphylococcus, Vibrio, Salmonella, Shigella, Neisseria, Mycobacterium tuberculosis and HIV. ${ }^{1}$ Of late, MDR 'superbugs' showing resistance against high-end antibiotics like carbapenems and colistin (last resort antibiotics) have been also identified. ${ }^{1}$
There are several determinants to the burgeoning AMR epidemic. One of the main compounders include public lack of knowledge regarding appropriate use of antibiotics. Self-medication and poor compliance are additional concerns. Inadequate infection control practices in hospitals also increases the risk of transmission of MDR pathogens to vulnerable subjects. Paucity in local susceptibility data makes it difficult to identify factors responsible for emergence of MDR pathogens.Besides the healthcare sector, antibiotic use in livestock such as in animal husbandry, fisheries and agricultural sectors for nontherapeutic purposes is also an unmeasured burden in India.

However, in the past few years, India has recognized AMR mitigation as a national priority. It has introduced 
catalogue of strategies, ranging from educational and awareness initiatives, infection control guidelines, audit and feedback, antimicrobial stewardship (AMS) and surveillance programmes to control the AMR crisis, Table 1.

Studies show that such resources have a positive impact on both clinical and economic outcomes. ${ }^{1}$ Experts are also mulling if antibiotics can be grouped into categories with recommendations when each category should be used, in line with the recent 2019 WHO AWaRe Classification ${ }^{2}$ (Figure 1) to ensure appropriate antibiotic usage in the country.

As India continues to formulate innovative action plans, this review highlights major policies introduced in recent years, expected to mitigate AMR trends significantly.

\section{Jaipur Declaration (2011)}

Acknowledging the growing global importance of AMR, the Health Ministers of all Member States of the WHO South-East Asia Region, including India, adopted the "Jaipur Declaration on Antimicrobial Resistance". The Declaration recognizes that it is imperative that the national governments accord utmost priority to this problem to preserve the efficacy of antibiotics in the fight against microbial diseases. India along with other nation signatories pledged to form multi-sectoral steering committees and formulate national antibiotic policies, laboratory-based antimicrobial surveillance programmes, hospital infectioncontrol policies and evidence-based national antimicrobial prescribing guidelines.

\section{National Policy for Containment of AMR (2011)}

A substantial step toward tackling AMR was taken in the form of a National Task Force on AMR Containment in 2010. Subsequently, the National Policy for Containment of Antimicrobial Resistance ${ }^{4}$ was included in the $12^{\text {th }} 5$-year plan $(2012$ - 2017). Major recommendations within the policy include launch of Schedule H1 (March 1, 2014) for prescription antibiotics and hospital-based sentinel surveillance system for monitoring AMR. ${ }^{5,6}$

The notification on Schedule H1 (Aug 30,2013) is particularly important. In India, currently 46 drugs (35 antimicrobials) have been placed under this category, mostly consisting cephalosporins, carbapenems, fluoroquinolones and

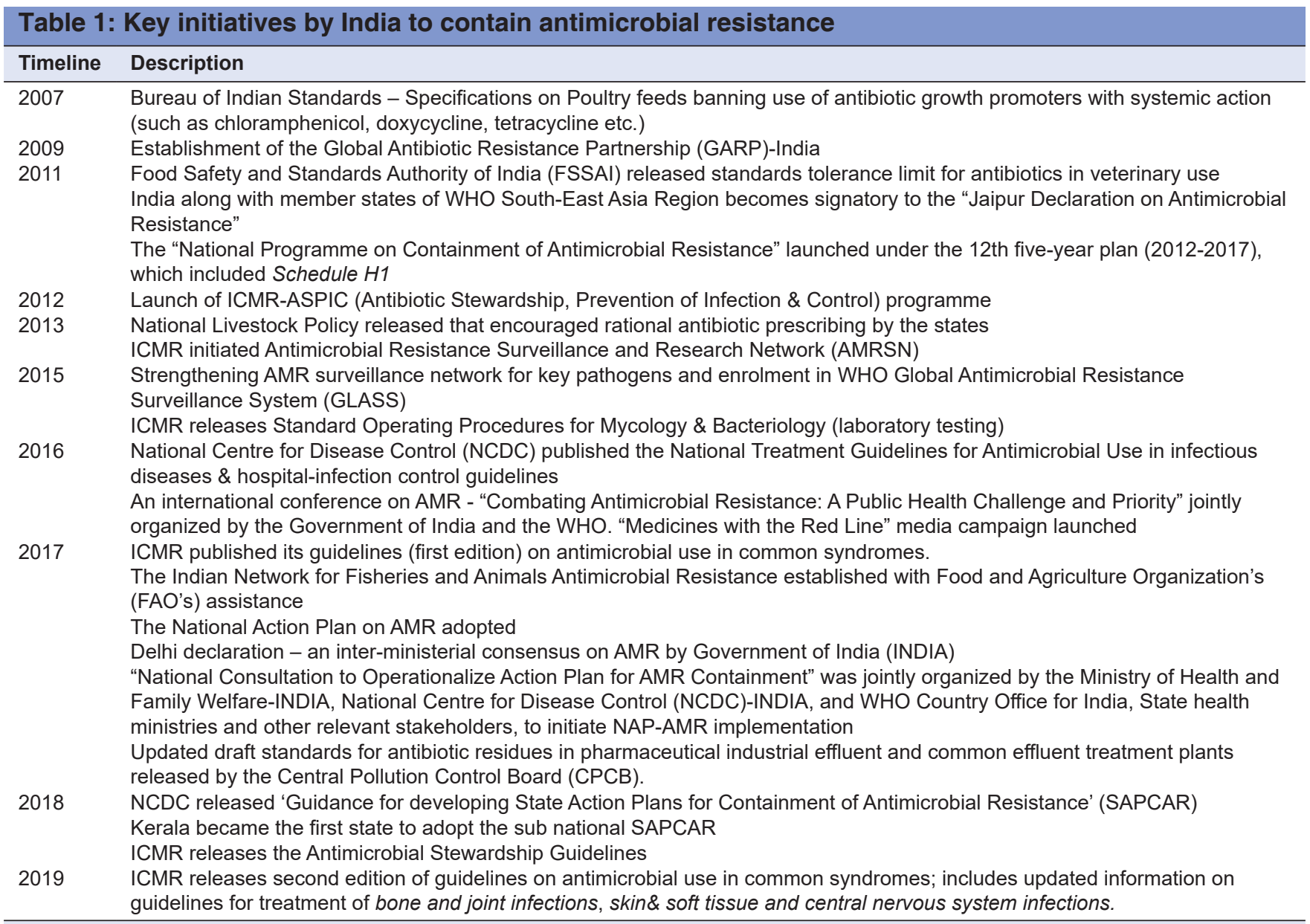

*The above list is not exhaustive. The list is created independently by GSK for description purposes 


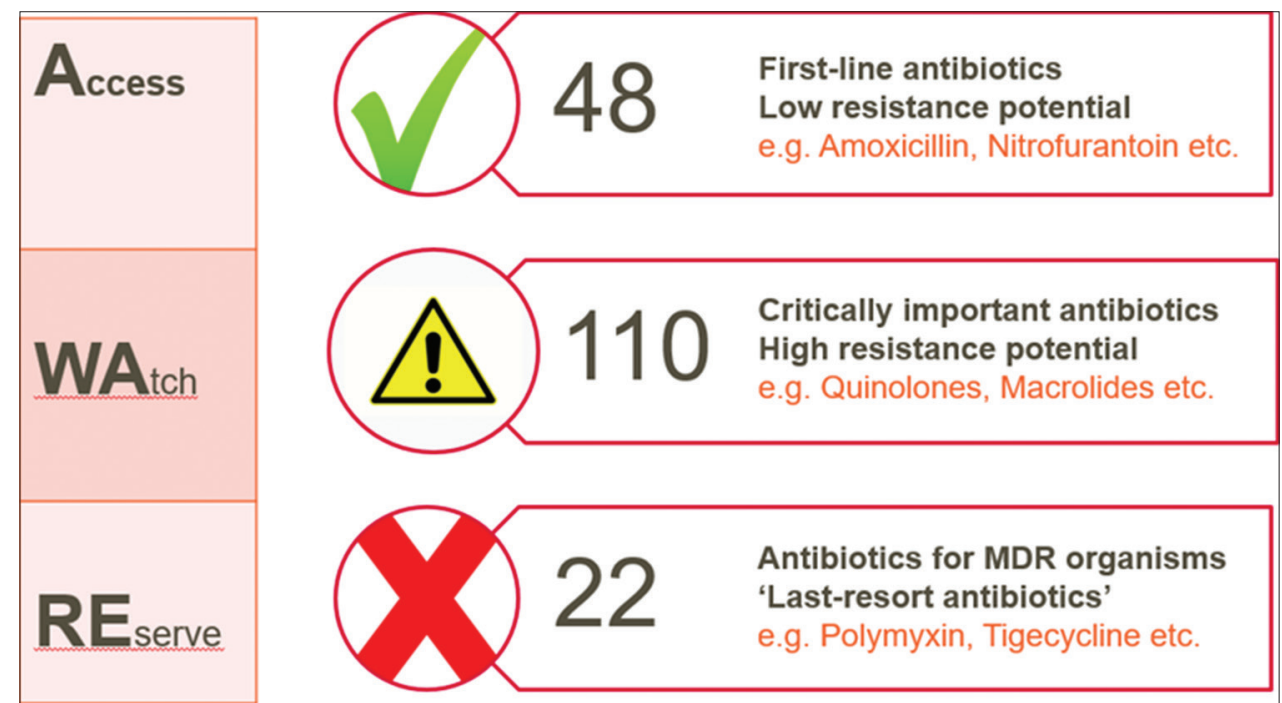

Figure 1: WHO AWaRe Classification of Antibiotics 2019

*This figure has been independently created by GSK for illustration purposes.

The 2019 WHO AWaRe Classification Database includes details of 180 antibiotics classified as Access, Watch or Reserve, their pharmacological classes, Anatomical Therapeutic Chemical (ATC) codes and WHO Essential Medicines List status.

ACCESS GROUP ANTIBIOTICS: Includes 48 antibiotics, 19 of which are included individually on the WHO Model List of Essential Medicines as first- or second -choice empiric treatment options for specified infectious syndromes. WATCH GROUP ANTIBIOTICS: This group includes antibiotics that have higher resistance potential and includes most of the highest priority agents among the Critically Important Antimicrobials for Human Medicine and/or antibiotics that are at relatively high risk of selection of bacterial resistance. The Watch group includes 110 antibiotics, 11 of which are included individually on the WHO Model List of Essential Medicines as first- or second -choice empiric treatment options for specified infectious syndromes. RESERVE GROUP ANTIBIOTICS: This group includes antibiotics and antibiotic classes that should be reserved for treatment of confirmed or suspected infections due to multi-drug-resistant organisms. Antibiotics in Reserve group should be treated as "last resort" options. 22 antibiotics have been classified as Reserve group. Seven Reserve group antibiotics are listed individually on the WHO Model List of Essential Medicines.

Source: AWaRe Classification Database https://apps.who.int/iris/bitstream/handle/10665/327957/WHO-EMP-IAU-2019.11-eng.xIsx?ua=1

anti-tubercular drugs. The packaging of these drugs will have a mandatory 'Schedule H1' warning with 'Rx' symbol in red. The drugs within the list can be sold by pharmaceutical chemist only against a valid prescription. The chemist will maintain a separate register where prescription data will be recorded. The register must be retained for at-least 3-years, subject to inspection by drug regulatory agencies.

Additionally, the policy introduces a system of colourcoding of third generation antibiotics and all newer molecules like carbapenems, tigecycline, daptomycin etc. for restricting their access to only tertiary hospitals. Other interventions such as recent ban on 343 irrational fixed dose combinations (FDC) were aimed to limit antibiotic abuse. ${ }^{7}$

\section{Chennai Declaration (2012)}

"A Roadmap to Tackle the Challenge of Antimicrobial Resistance - A Joint meeting of Medical Societies in India" was organized as a pre-conference symposium of the 2nd annual conference of the Clinical Infectious Disease Society (CIDSCON) at Chennai on August 24, 2012.8,9 This was the first ever meeting of medical societies in India on issue of tackling AMR, with a plan to formulate a road map to tackle the global challenge of AMR from the Indian perspective.
The meeting had representatives from most medical societies in India and eminent policy makers. A consensus, what came to be known as Chennai Declaration ${ }^{10}$ was adopted that essentially proposed a 5-year strategy to control AMR. This was a major landmark in India's fight against AMR. Major strategies proposed under the declaration include complete ban on OTC sale of antibiotics without prescription, in-hospital antibiotic usage monitoring, step up microbiology laboratory facilities, establishment of National AMR surveillance system etc.

\section{ICIMR - Antibiotic Stewardship, Prevention of Infection} \& Control Programme (2012)

The need for AMS practices in hospitals across the country has been evident since many years. In several cases, hospitals do not maintain records of antibiograms or do not have an antibiotic policy altogether. In this regard, ICMR launched the programme on Antimicrobial Stewardship, Prevention of Infection and Control (ASPIC) in 2012 through collaboration between the office of the National Chair of Clinical Pharmacology, ICMR and the Christian Medical College, Vellore. ${ }^{11}$ A national workshop was hosted as a part of a 1-year programme to develop capacity of key stakeholders in AMS. 
Anti-microbial Resistance Surveillance and Research Network (2013)

Previously, India did not have a national surveillance system to monitor AMR and this gap was evident when the NDM-1, story was published in $2010 .{ }^{12}$ To streamline data collection and have nation-wide picture, the ICMR in 2013 set up an Anti-microbial Resistance Surveillance and Research Network (AMRSN), ${ }^{13}$ which is currently networking the tertiary care hospitals in the country. The National Centre for Disease Control (NCDC) is the focal point for implementation of the programme. The overarching aim of this network is to understand the extent and pattern of AMR and use this evidence to guide strategies to control the spread of AMR.

Currently the AMRSN labs includes 20 state medical colleges from 18 states. The focus indication (pathogens) include (i) diarrhea (e.g., Shigella, Vibrio cholerae), (ii) enteric fever (e.g., S. Typhi, S. Paratyphi), (iii) sepsis caused by Enterobacteriaceae (e.g., E. coli, K. pneumoniae), (iv) other Gram-negative organisms (e.g., Pseudomonas aeruginosa, A. baumannii), (v) Gram-positive bacteria (e.g., MRSA and vancomycin-resistant enterococci [VRE]), (vi) fungal infections (e.g., Candida spp.), and (vii) respiratory pathogens (e.g., Streptococcus pneumoniae). These labs are required to submit specific AMR surveillance data on a quarterly basis and feedback is provided to the labs by NCDC regarding completeness of data etc. The data is then analyzed at NCDC on an annual basis. The AMRSN 2018 annual report was recently published, along with the AMR data emanating between January 2018 to December $2018 .^{14}$

\section{The Red Line Campaign (2016)}

In 2016, the Ministry of Health \& Family Welfare (MoH\&FW) launched the 'Red Line Campaign' at the 3-day International Conference on Combating Antimicrobial Resistance, held during February 2016. ${ }^{15,16}$ It was amuch-needed AMR awareness campaign, that directs patients not to use medicines marked with a red vertical line, comprising of antibiotics, without the prescription of a doctor. These medicines are called as the 'Medicines with the Red Line'. This campaign was intended at discouraging needless prescription and OTC sale of antibiotics. Additionally, a logo 'Use with Care' for antibiotics was launched. ${ }^{16}$ Some medicines, such as antibiotics already have the red line, but patients are often unaware of its meaning.

\section{Antimicrobial Stewardship Guidelines (2017)}

In November 2017, ICMR released the Antimicrobial Stewardship Guidelines, ${ }^{17}$ to mark the World Antibiotic Awareness Week (12 $2^{\text {th }}$ to $17^{\text {th }}$ November). It entails developing AMSP curriculum, conducting workshops and developing AMSP research projects. The aim of the guideline is to provide guidance to Indian hospitals to set up structure and process of AMSP. The audience for this document is hospital administrators and clinicians. Moreover, recognizing the need to create AMSP structures in hospitals across the country, ${ }^{18}$ the ICMR also carried out four workshops on AMSP capacity building across the country in the second quarter of 2017 (bttp:/ / iamrsn. icmr.org.in/index.php/events/amsp). More than 30 hospitals across the country participated in the workshop. Several deliverables were identified which could be initiated at the earliest, Table 2.

\section{National Action Plan (2017-2021)}

In May 2015, the 68 $8^{\text {th }}$ World Health Assembly (WHA) endorsed the Global Action Plan on Antimicrobial Resistance (GAP-AMR) - including AMR. ${ }^{19}$ The WHA resolution urged Member States to align their National Action Plan on AMR (NAP-AMR) with GAP-AMR by May 2017. To this effect, after consultation with various stakeholders, India released its final draft on NAP-AMR in April 2017, ${ }^{20}$ which was then submitted at the $70^{\text {th }}$ WHA in Geneva in May 2017. The 5-year NAP on AMR (2017-2021) outlines the priorities and implementation strategies for curbing AMR in India, Table 3.

In 2018, India released a guidance document ${ }^{21}$ for states to formulate region-specific AMR containing policies or State Action Plans for Containment of Antimicrobial Resistance (SAPCAR). Kerala became the first state to adopt the subnational SAPCAR.

ICMR Treatment Guidelines for Antimicrobial use in Common Syndromes (2019)

The Treatment Guidelines for Antimicrobial Use in Common Syndromes aims to rationalize the usage of antibiotics on National List of Essential Medicines (NLEM) and to establish consistency in the treatment of various infectious conditions. The first edition of evidence-based treatment guidelines for treatment of common syndromes was developed by ICMR in 2017. A comprehensive second edition ${ }^{22}$ was released on September 12, 2019 and includes updated information on guidelines for treatment of bone and joint infections, skin \& soft tissue and central nervous system infections with their dosing, route of administration and duration of therapy. Table 4 summarizes the steps of rational antimicrobial use in accordance with the 2019 guidelines.

\section{Technical challenges \& opportunities}

The increasing national focus on AMR underlines that the issue is cross-sectoral, affecting all strata of society. Apart from rational antibiotic prescribing, a proactive approach towards following issues can further mitigate the AMR crisis: 


\title{
Table 2: Recommendations for Indian hospital settings based on the ICMR-AMSP guideline
}

\author{
Guidelines features Description \\ Specific deliverables 1. Hospital antibiogram \\ 2. Hospital antibiotic policy including surgical prophylaxis based on antibiograms \\ 3. Culture of cultures: Point prevalence study \\ 4. Measurement of antibiotic consumption rate (DDD/DOT) \\ 5. Consider introducing audit and formulary restrictions \\ 6. Staff education: CME for hospital staff and for hospitals in surrounding areas
}

Structure Antibiotic stewardship team formed in hospitals will be responsible for implementing and monitoring AMSP. The team will coordinate the activities in connection with the hospital and pharmacy, governance, infection control and drug committees. The team must include, but not limited to physician or surgeon trained in infectious disease, a pharmacist, a clinical microbiologist, and infection control personnel.

Antibiogram \& antibiotic policy

Formularies \& guidelines Training

Monitoring

Goals \& measurable outcome

Audit \& feedback

Interventions

Education \& awareness

Research on AMR

Hospital-specific antibiograms to be generated periodically; guidelines for antibiotic to be based on antibiograms. Policy must consider site of infection (e.g., skin or soft-tissue infection, intra-abdominal etc.) and mention alternate treatment regimens.

Approvals for prescribing and dispensing specific drugs and for sale of certain non-prescription drugs to be made mandatory. Guidelines for antimicrobial treatment and prophylaxis need to be available in all healthcare systems. Periodical training and certification of hospital staff on AMSP is mandatory, and prescribers must have training on "Therapeutic guidelines for antimicrobial use".

Background information on current antibiotic use and prescription rates to be collected. Use of electronic patient records to track prescription and antibiotic usage trends to be devised. Expenditure on antibiotics over time must be monitored.

1. The process measures include compliance with surgical prophylaxis prescribing, and 'care bundles' [three-day antibiotic review bundle, VAP bundle].

2. The outcome measures include antimicrobial usage rates, bacterial culture rate, resistance rates, Clostridium difficile rates, and length of hospital stay etc.

3. The balancing measures are mortality rates, treatment-related toxicity, rates of complications and surgical site infections, admissions in ICU and readmission within 30 days of discharge.

Review of prescriptions, laboratory results, clinical notes etc. and most importantly audit of carbapenem and polymyxin use in intensive-care settings.

Therapy based on standard guidelines and patients' clinical status to control use of restricted antimicrobials for empirical treatment. Other interventions include directed therapy based on early microscopy tests, antibiotic "time outs", de-escalation of therapy, dose optimization, change of broad-spectrum antibiotics after culture results are available and shortening treatment duration in prophylactic use.

Medical education curriculum should include AMSP as part of the main course for HCPs. It is also important to create awareness among patients, healthcare workers, administrators and governing authorities through advertising, media and messages.

AMS research focused on novel strategies of stewardship, implementation and impact of AMSP, point prevalent studies, effective interventions, surveillance and management of antimicrobial usage data, needs be devised for Indian settings

The table has been adapted from ICMR-AMSP guidelines.

AMR, Antimicrobial resistance; DDD, defined daily dose; DOT, days of therapy; VAP; Ventilator-associated pneumonia; CME, continuing medical education; AMS, Antimicrobial stewardship; AMSP, Antimicrobial stewardship programme; HCP, Health-care professionals.

Source: ICMR-AMSP guidelinehttp://iamrsn.icmr.org.in/images/pdf/AMSP_Guidelines_final.pdf

\begin{tabular}{|c|c|}
\hline $\begin{array}{l}\text { Strategic } \\
\text { priorities }\end{array}$ & Main objective \\
\hline $\begin{array}{l}\text { Strategic } \\
\text { priority \#1 }\end{array}$ & $\begin{array}{l}\text { Improve awareness and understanding of AMR through } \\
\text { effective communication, education, and training }\end{array}$ \\
\hline $\begin{array}{l}\text { Strategic } \\
\text { priority \#2 }\end{array}$ & $\begin{array}{l}\text { Strengthen knowledge and evidence through } \\
\text { surveillance }\end{array}$ \\
\hline $\begin{array}{l}\text { Strategic } \\
\text { priority \#3 }\end{array}$ & $\begin{array}{l}\text { Reduce the incidence of infection through effective } \\
\text { infection, prevention, and control }\end{array}$ \\
\hline $\begin{array}{l}\text { Strategic } \\
\text { priority \#4 }\end{array}$ & Optimize the use of antimicrobial agents in all sectors \\
\hline $\begin{array}{l}\text { Strategic } \\
\text { priority \#5 }\end{array}$ & $\begin{array}{l}\text { Promote investments for AMR activities, research, and } \\
\text { innovations }\end{array}$ \\
\hline $\begin{array}{l}\text { Strategic } \\
\text { priority \#6 }\end{array}$ & $\begin{array}{l}\text { Strengthen India's leadership on AMR by means of } \\
\text { collaborations on AMR at international, national, and } \\
\text { sub-national levels }\end{array}$ \\
\hline
\end{tabular}

Within each strategic priority and focus area, strategic interventions, key activities and outputs have been defined with tentative responsibility and timelines - short (within 1 year), medium (between 1 and 3 years) and long-term (between 3 and 5 years). Source: National Action Plan on Antimicrobial Resistance (2017-2021) https://ncdc.gov.in/WriteReadData/linkimages/AMR/File645.pdf

\section{Improvement in perception of AMR}

The GAP-AMR highlighted important deficits in the understanding of what antibiotics are, how they should be used and when to take them. Instances across the world indicate that integrating concepts of AMR in public-health education can have a beneficial impact. ${ }^{23}$ India has started focusing on the component of training in infectious diseases (apart from tuberculosis) through various programmes, e.g. ASPIC, ICMR-AMRSN etc. Providing similar but expanded training in the society can empower people to understand the appropriateness of treatment. India has already shown remarkable reductions in smoking in buildings and workplaces through regulation and behavior change communication. In this regard, successful media campaigns harnessing celebrity power championing for AMR could add benefit, as with campaigns on polio vaccination and tuberculosis screening. 


\title{
Table 4: Steps of rational antibiotic use (2019 ICMR guidelines on antimicrobial use)
}

\author{
Steps Description \\ Step \#1 Making a clinical diagnosis \\ radiology) to make a diagnosis of infection. Thought process must include following questions: \\ I. Is it an infection? \\ II. Risk assessment of how likely is it that the patient has an infection? \\ III. What are the possible non-infectious mimics? \\ IV. Have we taken the appropriate cultures to confirm the final diagnosis? \\ Step \#2 Limiting empiric antibiotic therapy to genuine seriously ill patients \\ then plan about the duration of therapy. \\ Step \#3 Know your bugs \\ I. Identify the clinical syndrome \\ II. Elucidate possible sources of infection \\ III. Predict possible microbial pathogens \\ IV. Predict the local resistance pattern based on institutional antibiogram \\ Step \#4 Choose the appropriate antibiotic \\ I. Based on the spectrum of the antibiotic considering possible resistant patterns \\ II. Use the correct dose, route and duration \\ III. Ensure chosen antibiotic has adequate tissue penetration at the site of infection \\ IV. Optimize PK-PD parameters according to co-morbidities
}

An accurate clinical diagnosis is more helpful rather than blindly relying on tests (procalcitonin levels, WBC counts, cultures or

Empiric antibiotic therapy is ONLY recommended for a select group of patients after taking appropriate cultures (in cases like febrile neutropenia, severe sepsis and septic shock, necrotizing fasciitis, community acquired pneumonia, ventilator associated pneumonia). It is important to start smart and then focus, i.e., evaluate if empiric therapy can be justified or de-escalated and

Step \#5 De-escalation/modification

I. Modify empiric broad spectrum antibiotics depending on culture and antimicrobial susceptibility reports and patient status

II. Stop polymyxins and glycopeptides, if no carbapenem resistant organisms (CRO) or methicillin resistant Staphylococcus aureus (MRSA) identified on cultures

III. Avoid double or redundant gram negative or anaerobic coverage

IV. Discontinue antibiotics if a non-infectious mimic identified

V. De-escalate combination therapy to a single agent

VI. Change a broad-spectrum antibiotic to a narrow spectrum one

VII. Change intravenous to oral antibiotics

Step \#6 Stop antibiotics in the following clinical situations

I. Respiratory tract syndromes (e.g. viral pharyngitis - viral rhinosinusitis - viral bronchitis - non-infectious cardio-pulmonary syndromes misdiagnosed as pneumonia)

II. Skin and Soft Tissue Infections (e.g. subcutaneous abscesses, lower extremity stasis dermatitis)

III. Asymptomatic bacteriuria and pyuria including in catheterized patients

IV. Microbial colonization and culture contamination

V. Low grade fever

Step \#7 Reduce the duration of therapy

Duration of therapy should be optimized to minimum possible to reduce selection pressure. Practice guidelines and

recommendations for optimum duration of therapy for various infectious disease syndromes suggest the following durations:

1. Community acquired pneumonia: 5 days

2. Hospital acquired pneumonia: 8 days

3. Skin and Soft tissue infections: 5 days

4. Urinary tract infections

a. Cystitis: 3-5 days

b. Pyelonephritis: 5-14 days

c. Catheter associated: 7 days

5. Staphylococcal aureus bacteremia

a. low risk of complications $=2$ weeks; high risk of complications $=4-6$ weeks

b. Intra-abdominal infection: 4-7 days

c.Surgical antibiotic prophylaxis: 1 dose

Step \#8 Optimize PK-PD parameters

Exposure of the infective agent to the unbound antibiotic drug fraction at the relevant effect site seems to be the most important factor. Optimizing PK/PD parameters include loading doses when needed, therapeutic drug monitoring for toxicity and efficacy and optimization of drug infusion or administration. For e.g.,

Loading dose of Colistin 9 million units stat and then followed by 3 million units Q8H or 4.5 million units Q12H [to target

Colistin Average Steady State Plasma Concentration (Css, avg $=2-2.5 \mathrm{mg} / \mathrm{L}$ )

Inj. vancomycin $1 \mathrm{~g} \mathrm{IV} \mathrm{Q12H}$ and dose to be adjusted to maintain a trough level between $15-20 \mu \mathrm{g} / \mathrm{ml}$ [however there are increasing recent data that suggests that AUC/MIC may be a better indicator of clinical efficacy than a trough level]

Extended infusion of $\beta$ lactams

The table has been adapted from ICMR Treatment Guidelines for Antimicrobial Use in Common Syndromes (2019)

Source: ICMRTreatment Guidelines for Antimicrobial Use in Common Syndromes (2019) https://www.icmr.nic.in/sites/default/files/guidelines/Treatment_Guidelines_2019_Final.pdf 
Scaling up AMS strategy

The WHO recently published AMR surveillance data from 169-member countries, mentioning the lack of national surveillance data on MDR pathogens 14 other member countries, including India. ${ }^{24}$ The ICMR-AMRSN partly addresses this unmet need with a structured nationwide surveillance of high-priority pathogens in clinical settings \& animal husbandry, which was previously inadequate in most cases. Expansion of AMRSN to include all healthcare set-ups, including primary and secondary care, would help build a comprehensive database.

Consequently, a systematic reporting system for hospitalacquired infection can be immensely helpful in India. While recent studies have indicated that hospitals in India have initiated written infection control policy, ${ }^{11,25}$ studies looking at implementation are still needed. In this regard, a strategy for rapid scale-up of AMSP and strengthening of resource training becomes a priority, since successful stewardship models in India are currently limited. ${ }^{26}$

\section{Restricting antibiotic misuse}

To restrict antibiotic misuse in India, first step includes interventions like antibiotic surveillance studies, ${ }^{26}$ periodic prescription audits, drug utilization studies and monitored generic drug that quantify the AMR crisis. They can also aid in assessment of antibiotic consumption trends helping policy makers immensely.

Next step includes reducing self-medication among consumers, partly encouraged by easy OTC access to prescription antibiotic. Equally important will be restricting the use of substandard antimicrobials. While stricter oversight is necessary in this regard, provisions also need to be balanced against the need to maintain access for the significant proportion of the population that lacks access to quality healthcare. Data shows that surveillance and monitoring of usage/sale of antibiotics can be effective, as was seen with the government's restriction on bedaquiline. ${ }^{27}$

\section{Addressing environmental issues contributing to AMR}

Public-health education must include environmental issues contributing to AMR, including knowledge of soil related factors, animal husbandry, waste management, potable and wastewater, and food safety. Healthcare education must also address the need to understand biological plausibility of environmental determinants playing role in the propagation of AMR. ${ }^{28,29}$ For instance, preliminary studies indicated continued use of pre-mixed feeds with antibiotics (often high-end antibiotics like colistin). ${ }^{30,31}$ With the likelihood of increased demand for meat and poultry globally (expected to grow $312 \%$ by 2030 ), emphasis on continued scrutiny of implementation measures by broadbased surveillance systems will be crucial.
Newer antibiotics: Addressing the innovation crisis Despite increased research and development expenditure, novel anti-infectives have been hard to develop. Most of the research $(70 \%)$ has concentrated on newer congener formulations with characterization of antimicrobial properties of known synthetic or natural products orchemical modification of existing compounds rather than on attempting to discover new antimicrobial agents. ${ }^{32}$ In fact, most studies have been limited to in vitro experiments or small-scale animal studies, limiting clinical evaluation of any first-in-class antimicrobial agent. ${ }^{33,34}$ Currently, only few organizations are focusing on development of 'superbug antibiotics' ${ }^{35}$

Fostering AMR research through greater investments Traditionally, research in the anti-infective arena has largely been focused on the disease epidemiology. However, there is insufficient research into the mechanisms of AMR, including use of rapid antimicrobial susceptibility diagnostics, which could provide a better guide to antimicrobial prescribing. Data sharing mechanism are needed to ensure that these results are available to guide policy makers and clinicians in a timely manner. ${ }^{36}$ Incentivized preclinical research or early clinical development could also help in this regard. WHO already advocates institutions allocating at least $2 \%$ of the total healthcare budget towards research. ${ }^{37} \mathrm{~A}$ similar allocation would help donor agencies to mobilize their resources and plan an effective research programme.

\section{Galvanizing public-private partnerships to increase outreach}

Sustainable solutions to curb AMR can be achieved by creating a broad industry momentum and facilitating collaboration between the public and private sectors. The AMR Industry Alliance ${ }^{38}$ is a welcome step in this regard, being one of the largest coalitions set up to provide solutions to curb AMR, with over 100 biotech, diagnostics, generics and research-based pharmaceutical companies and associations joining forces.Partnering with bio/ pharmaceutical organizations in their AMR campaigns ${ }^{39}$ could also help increase physician outreach in a vast country like India.

\section{CONCLUSION}

India has introduced promising measures for tackling AMR, that requires significant efforts from all stakeholders involved. The issue AMR awareness although slow to gain momentum but is now dominating the national conscience. Robust increased intersectoral co-ordination and publicprivate partnerships will likely strengthen country's fight against AMR. 


\section{ACKNOWLEDGEMENTS}

We express our heartfelt thanks to the Dr. Puja Kochhar (Medical Director \& Team Leader - Infectious Diseases; Classic \& Established Products, GlaxoSmithKline), Dr. Didem Torumkuney (Scientific Director, Global SOAR Lead, GlaxoSmithKline) \& Charles Miller (Publication Lead, GlaxoSmithKline) for review and support during this project.

\section{REFERENCES}

1. World Health Organization. Prevention and containment of antimicrobial resistance. Report of a regional meeting Chiang Mai, Thailand; 2010. [cited 2020 May 7].

http://www.searo.who.int/LinkFiles/BCT_Reports_SEAHLM-408.pdf.

2. Ng CK, Wu TC, Chan WM, Leung YS, Li CK, Tsang DN, et al. Clinical and economic impact of an antibiotic stewardship programme in a regional hospital in Hong Kong. Qual Saf Health Care. 2008; 17:387-392.

https://doi.org/10.1136/qshc.2007.023267

3. WHO releases the 2019 AWaRe Classification Antibiotics [monograph on the internet].2019 [cited 2020 May 7].

https://www.who.int/medicines/news/2019/WHO_releases2019 AWaRe_classification_antibiotics/en/

4. Jaipur Declaration on AMR[monograph on the internet].2020 [cited 2020 May 7].

https://apps.who.int/iris/bitstream/handle/10665/205397/B4828. pdf?sequence $=1$ \&isAllowed $=y$

5. National Policy for Containment of Antimicrobial Resistance in India [monograph on the internet]. Directorate General of Health Services. Nirman Bhawan, New Delhi: Ministry of Health \& Family Welfare; 2011 [cited 2020 May7].

https://mohfw.gov.in/sites/default/files/3203490350abpolicy\%20 $\% 281 \% 29$.pdf

6. New Delhi: Department of Health and Family Welfare, Government of India; 2013. Gazette notification G.S.R. 588(E). The Gazette of India dated August 30, 2013 [serial on the internet]; pp. 4-8 [cited 2020 May 7].

https://cdsco.gov.in/opencms/opencms/system/modules/ CDSCO.WEB/elements/download_file_division.jsp?num_ id $=$ MTMONA ==

7. Ban 343 irrational FDC medicines, say experts [monograph on the internet]. Deccan Herald. 2018July [cited 2020 May 7].

https://www.deccanherald.com/national/ban-343-irrationalfdc-683799.html

8. Holmes $\mathrm{AH}$ and Sharland M. The Chennai Declaration: India's landmark national commitment to antibiotic stewardship demonstrates that 'truth alone triumphs'. J Antimicrob Chemother. 2013;68(7):1453-1454.

https://doi.org/10.1093/jac/dkt062

9. Ghafur A, Mathai D, Muruganathan A, Jayalal JA, Kant R, Chaudhary D, et al. The Chennai declaration: A roadmap to tackle the challenge of antimicrobial resistance. Indian J Cancer. 2013;50:71-73.

https://doi.org/10.4103/0019-509X.104065

10. Voss A andGhafur A. "The Chennai declaration" - Indian doctors" fight against antimicrobial resistance. Antimicrob Resist Infect Control. 2013;2:7. https://doi.org/10.1186/2047-2994-2-7

11. Chandy SJ, Michael JS, Veeraraghavan B, Abraham OC, Bachhav SS and Kshirsagar NA. ICMR programme on Antibiotic Stewardship, Prevention of Infection \& Control (ASPIC). Indian J Med Res. 2014; 139:226-230.

12. Raghunath D. New metallo $\beta$-lactamase NDM-1. Indian J Med Res. 2010; 132:478-481.

13. Anti Microbial Resistance Surveillance and Research Network (AMRSN) Initiative [monograph on the internet]. ICMR 2013 [cited 2020 May7]. https://bic.icmr.org.in/iamrsn/

14. Annual Report 2018. Anti-Microbial Resistance Surveillance and Research Network (AMRSN) - January 2018 to December 2018 [monograph on the internet]. 2018 [cited 2020 May 7]. http://iamrsn.icmr.org.in/images/pdf/Annual_Report_2018.pdf

15. India draws a red line under antibiotic misuse. BMJ 2016;352:i1202. https://doi.org/10.1136/bmj.i1202

16. India Lauded for Red Line Campaign on Antibiotics - The Hindu [monograph on the internet]. 2016 Sep [updated 2016 Sep 16; cited 2020 May 7].

http://www.thehindu.com/news/national/india-lauded-for-redline-campaign-on-antibiotics/article8622474.ece

17. Antimicrobial Stewardship Guidelines [monograph on the internet]. ICMR 2018 [cited 2020 May 7] http://icmr.nic.in/sites/default/files/guidelines/AMSP.pdf

18. Rattan A, Bhujwala RA, Kumar R and Safaya AN. Organization of infection control program. J Acad Hosp Adm. 1992; 4:21-25.

19. Global Action Plan on Antimicrobial Resistance [monograph on the internet]. WHO 2015 [cited 2020 May 7].

http://www.wpro.who.int/entity/drug_resistance/resources/ global_action_plan_eng.pdf

20. National Action Plan on Antimicrobial Resistance (NAP AMR), 2017-2021, India: Ministry of Health and Family Welfare, Government of India [serial on the internet]; 2017 [cited 2020 May7].

http://www.searo.who.int/india/topics/antimicrobial_resistance/ nap_amr.pdf

21. Ministry of Health and Family Welfare, Government of India. Guidance for developing State Action Plan for Containment of Antimicrobial Resistance (SAPCAR). National Centre for Disease Control 2018 [cited 2020 May 7]. https://ncdc.gov.in/WriteReadData/linkimages/AMR/SAPCAR.pdf

22. Treatment Guidelines for Antimicrobial Use in Common Syndromes 2019. Indian Council of Medical Research (ICMR). 2019 Sep [cited 2020 May 7].

https://www.icmr.nic.in/sites/default/files/guidelines/Treatment_ Guidelines_2019_Final.pdf

23. McNulty CA, Lecky DM, Farrell D, Kostkova P, Adriaenssens N, Koprivová Herotová T, et al. Overview of e-bug: An antibiotic and hygiene educational resource for schools. J Antimicrob Chemother. 2011; 66Suppl 5:v3-12.

https://doi.org/10.1093/jac/dkr119

24. World Health Organization (WHO). Antimicrobial resistance: global report on surveillance. 2014 [serial on the internet];1-256 [cited 2020 May 7].

http://apps.who.int/iris/bitstream/10665/112642/1/9789241564748_ eng.pdf

25. Singh S, Menon VP, Mohamed ZU, Kumar A, Nampoothiri V, Sudhir $S$, et al. Implementation of antibiotic stewardship: A South Indian experience. Open Forum Infect Dis. 2017; 4Suppl 1:S267-S268. 
https://doi.org/10.1093/ofid/ofy290

26. Torumkuney D, Chaiwarith R, Reechaipichitkul W, Malatham K, Chareonphaibul V, Rodrigues C, et al. Results from the Survey of Antibiotic Resistance (SOAR) 2012-14 in Thailand, India, South Korea and Singapore [published correction appears in $\mathrm{J}$ Antimicrob Chemother. 2016;71:3628]. J Antimicrob Chemother. 2016;71 Suppl 1(Suppl 1):i3-i19. https://doi.org/10.1093/jac/dkw073

27. Krishnan V. 'India's Refusal to Scale up Bedaquiline is Really the World's Problem' [monograph on the internet]. The Hindu. 2017 Jan [cited 2020 May 7].

https://www.pressreader.com/india/the-hindu/20170108/2818 01398643995

28. Walsh TR, Weeks J, Livermore DM and Toleman MA Dissemination of NDM-1 positive bacteria in the New Delhi environment and its implications for human health: An environmental point prevalence study. Lancet Infect Dis. 2011; 11:355-362.

https://doi.org/10.1016/S1473-3099(11)70059-7

29. Djordjevic SP, Stokes HW and Chowdhury PR. Mobile elements, zoonotic pathogens and commensal bacteria: conduits for the delivery of resistance genes into humans, production animals and soil microbiota. Front Microbiol. 2013; 4:86. https://doi.org/10.3389/fmicb.2013.00086

30. Comments with regard to placing of meat and poultry products on the Indian market. New Delhi: Controller of Publications, Ministry of Health and Family Welfare, Government of India [monograph on the internet]. Food safety and Standards Authority of India[cited 2020 May 7].

http://old.fssai.gov.in/Portals/0/Pdf/Draft_Meat_Poultry_ Comments.pdf.

31. Chattopadhyay MK. Use of antibiotics as feed additives: a burning question. Front Microbiol. 2014; 5:334.

https://doi.org/10.3389/fmicb.2014.00334
32. Coates AR, Halls $\mathrm{G}$ and $\mathrm{Hu} \mathrm{Y}$. Novel classes of antibiotics or more of the same?. Br J Pharmacol. 2011; 163:184-194.

https://doi.org/10.1111/j.1476-5381.2011.01250.x

33. Cheesman MJ, llanko A, Blonk B and Cock IE. Developing New Antimicrobial Therapies: Are Synergistic Combinations of Plant Extracts/Compounds with Conventional Antibiotics the Solution?. Pharmacogn Rev. 2017; 11:57-72. https://doi.org/10.4103/phrev.phrev_21_17

34. Simpkin VL, Renwick MJ, Kelly R and Mossialos E. Incentivising innovation in antibiotic drug discovery and development: progress, challenges and next steps. J Antibiot (Tokyo). 2017; 70:1087-1096. https://doi.org/10.1038/ja.2017.124

35. The Indian Companies Taking on Superbugs [monograph on the internet]. BBC News; 2017 Nov [cited 2020 May 7]. http://www. bbc.com/news/world-asia-india-42063013

36. Das B, Chaudhuri S, Srivastava R, Nair GB and Ramamurthy T. Fostering research into antimicrobial resistance in India. BMJ. 2017; 358:j3535 https://doi.org/10.1136/bmj.j3535

37. Health Sector Budget Advocacy: A guide for civil society organizations [monograph on the internet]. WHO [cited 2020 May 7].

https://www.who.int/pmnch/media/news/2012/201205_health_ sector_budget_advocacy.pdf

38. AMR Industry Alliance [monograph on the internet]. 2018 [cited 2020 May 7].

https://www.amrindustryalliance.org/why-the-amr-industryalliance/

39. GSK - Appropriate Use Initiative [monograph on the internet]. 2018 [cited 2020 May 7].

https://www.amrindustryalliance.org/case-study/gskappropriate-use-initiatives/

\section{Author's Contributions:}

SL, RR, KD- Conceptualized and designed the study, literature search, prepared first draft of the manuscript, critical revision of the manuscript;

YC, AP, AG, BK- Conceptualized the study, Interpretation, critical revision of the manuscript; SL, AP, BK- Concept of the study, literature search, review of the study.

Work Attributed to:

Medical \& Regulatory Affairs, GlaxoSmithKline (India).

\section{Orcid ID:}

Dr. Sandeep Lahiry- (D https://orcid.org/0000-0002-6919-0530

Dr. Rajesh Ramalingam- (i) https://orcid.org/0000-0003-0690-1283

Dr. Krunal Dalal- (i) https://orcid.org/0000-0001-5189-7469

Dr. Ashwini Pawar- (1) https://orcid.org/0000-0003-1884-2399

Dr. Yashpal Chugh- https://orcid.org/0000-0002-5591-6169

Dr. Alap Gandhi- (1) https://orcid.org/0000-0002-7002-250X

Dr. Bhavesh Kotak- (1) https://orcid.org/0000-0003-0992-1028

Source of funding: GlaxoSmithKline (India), Conflicts of Interest: All authors are employees of GlaxoSmithKline (India). None of the authors hold any shares of GlaxoSmithKline group of companies. 